\title{
Establecimiento de un protocolo para la inducción de embriogénesis somática indirecta en Allium Sativum (Ajo Criollo Costarricense)
}

\section{Establishment of a protocol for the induction of indirect somatic embryogenesis in Allium sativum (Costa Rican Creole Gralic)}

William Watson-Guido ${ }^{1}$, Vilma Jimenez-Bonilla², Jaime Brenes-Madriz ${ }^{3}$

Fecha de recepción: 4 de febrero de 2020

Fecha de aprobación: 3 de junio de 2020

Watson-Guido, W; Jimenez-Bonilla, V; Brenes-Madriz, J. Establecimiento de un protocolo para la inducción de embriogénesis somática indirecta en Allium Sativum (ajo criollo costarricense). Tecnología en Marcha. Vol. 34-2. Abril-Junio 2021. Pág 178-186.

doi) https://doi.org/10.18845/tm.v34i2.4984

1 Ingeniero en Biotecnología. Costa Rica. Instituto Tecnológico de Costa Rica. Costa Rica. Correo electrónico: willwatqui@gmail.com. (iD) https://orcid.org/0000-0002-2704-5159

2 Lic. en Biología. Centro de Investigaciones en Biotecnología, Escuela de Biología. Instituto Tecnológico de Costa Rica. Costa Rica..Correo electrónico: vijimenez@tec.ac.cr

3 Ing. Agrónomo. Centro de Investigaciones en Biotecnología. Escuela de Biología. Instituto tecnológico de Costa Rica. Costa Rica. Correo electrónico: jabrenes@tec.ac.cr. 


\title{
Palabras clave
}

Ajo; embriogénesis indirecta; callogénesis; embrión somático.

\section{Resumen}

El ajo (Allium sativum), presenta propiedades medicinales y culinarias, así como propiedades repelentes aprovechables en la agricultura orgánica, que lo hace un cultivo con alta demanda en nuestro país y en el resto del mundo. En Costa Rica se encuentra un material nativo, muy apreciado por el consumidor nacional por sus cualidades organolépticas, como sabor y olor. La falta de semilla de calidad y falta de material adaptado a condiciones tropicales, así como la competencia por precio con el ajo importado de China y Guatemala (ya que se importa a precios muy bajos por kilo), hace que se dificulte colocarlo en los mercados nacionales. Por lo anterior se planteó esta investigación con el objetivo de obtener embriones somáticos vía indirecta y regenerar plántulas libres de virus y otros patógenos, para ser utilizadas como método de propagación vegetativa. Los explantes utilizados para la inducción de callogénesis fueron meristemos radicales. El callo se indujo en medio de cultivo M\&S (1962), con sacarosa al $3 \%$ y $\mathrm{pH}$ 5,7, suplementado con 1,0 mg/L, ácido naftalenacético (ANA), 2,0 mg/L bencil-amino purina (BAP) y 0,5 mg/L ácido 2,4-diclorofenoxiacético (2,4-D). La proliferación de los callos de obtuvo al subcultivarlos en el medio M\&S (1962), con sacarosa al 3\% y pH 5,7 suplementado $1 \mathrm{mg} / \mathrm{L}$ BAP y $0,25 \mathrm{mg} / \mathrm{L}$ de 2,4-D, al mes se observó la formación de embriones globulares la maduración embrionaria se obtuvo con la adición de 0,5 mg/L de $A_{3}$ y para la germinación con $0,5 \mathrm{mg} / \mathrm{L}$ de BAP.

\section{Keywords}

Garlic; indirect embryogenesis; callogenesis; somatic embryo.

\begin{abstract}
The garlic (Allium sativum), has medicinal and culinary properties, as well as repellent properties that can be used in organic agriculture, which makes it a crop with high demand in our country and in the rest of the world. In Costa Rica there is a native material, much appreciated by the national consumer for its organoleptic qualities, such as taste and smell. The lack of quality seed and lack of material adapted to tropical conditions, as well as the price competition with garlic imported from China and Guatemala (since it is imported at very low prices per kilo), makes it difficult to place it in the markets Nationals Therefore, this research was proposed with the aim of obtaining somatic embryos indirectly and regenerating seedlings free of viruses and other pathogens, to be used as a method of vegetative propagation. The explants used for the induction of callogenesis were radical meristems. The callus was induced in M\&S culture medium (1962), with $3 \%$ sucrose and $\mathrm{pH} 5,7$, supplemented with 1,0 mg/L, naphthalenacetic acid (ANA), 2,0 mg/L benzyl-amino purine (BAP) and 0,5 mg/L 2,4-dichlorophenoxyacetic acid $(2,4-D)$. The proliferation of the calluses was obtained by subculturing them in the M\&S medium (1962), with $3 \%$ sucrose and $\mathrm{pH}$ 5,7 supplemented $1 \mathrm{mg} / \mathrm{L}$ BAP and 0,25 mg/L of 2,4-D, per month The formation of globular embryos was observed. Embryonic maturation was obtained with the addition of $0,5 \mathrm{mg} / \mathrm{L}$ of $\mathrm{AG} 3$ and for germination with $0,5 \mathrm{mg} / \mathrm{L}$ of BAP.
\end{abstract}




\section{Introducción}

El ajo, Allium sativum, es una monocotiledónea de la familia Alliceae y del orden Asparagales [1]. Presenta una cabeza compuesta de 10 a 30 dientes o bulbillos, los cuales son utilizados como material de siembra, ya que la semilla botánica no es viable. Por esta razón se le considera como una especie apomíctica obligada; término que se refiere a su capacidad para producir embriones sin existir fecundación previa [2].

En Costa Rica, al ajo cultivado se le llama ajo criollo y se clasifica entre los ajos violetas o asiáticos caracterizado por su corto ciclo de reproducción y corta dormancia y con bajos requerimientos de frío[3], además poseen un sabor y olor fuerte, lo que lo convierte en un cultivo apetecido para los consumidores y una opción para los agricultores. No obstante la presencia de problemas fitosanitarios, aunado a problemas en cuanto al número y tamaño de dientes, variabilidad del diámetro del bulbo y la escases de semilla de calidad $[4,1]$ hacen que la producción sea baja.

Su cultivo se limita a zonas con un rango altitudinal de 900 a 2000 msnm., siendo las principales regiones de siembra la zona norte de la provincia de Cartago (Llano Grande, Tierra Blanca, Cot y Pacayas), además de Santa Ana de San José y San Luis de Santo Domingo de Heredia, esta producción no suple ni el 10\% del consumo nacional [1,2].

Para superar los problemas de calidad y cantidad de semilla, se han utilizado técnicas de cultivo in vitro. Estas técnicas han adquirido un potencial enorme para la propagación masiva de plantas, mediante vía organogénica y embriogénica; la diferencia entre ellas es que la primera da origen a órganos unipolares y la embriogénesis genera estructuras bipolares similares a los embriones, con eje radicular y apical, los cuales no poseen ninguna conexión vascular con el explante que le dio origen. Según los reguladores de crecimiento utilizados en el medio de cultivo se pueden generar embriogénesis somática directa e indirecta. La embriogénesis indirecta se divide en varias etapas, iniciando en la formación de callo, regeneración de callo embriogénico, desarrollo de los embriones somáticos, proliferación de estos embriones, maduración, germinación y conversión de los embriones a plantas completas [5]. Con la aplicación de esta técnica es posible obtener un incremento en el número de plantas, la sanidad del material y facilitar el transporte de material vegetal entre países.

En el ajo, al considerarse una especie apomíctica, la embriogénesis somática indirecta se vuelve una técnica importante, para producir material de ajo, de forma masiva y genéticamente igual a la planta madre.

\section{Materiales y métodos}

\section{Establecimiento in vitro del explante}

Los dientes de ajo fueron suministrados por agricultores de la zona de Llano Grande de Cartago y se tomó como explante segmentos de la base del diente de aproximadamente $5,0 \mathrm{~mm}$ de longitud, a los cuales se les eliminaron las raíces. Se desinfectaron utilizando la metodología establecida por [2]. Los dientes se desprendieron de la túnica y se lavaron con agua y jabón y luego se sumergieron en una solución con 5 g/L de Agry-micin® y 5 g/L Zetaran $®$ y 3 gotas de Tween $20 \circledR$ por un período de 45 minutos en agitación constante a $400 \mathrm{rpm}$. Posteriormente se realizaron tres lavados con agua destilada estéril y luego una desinfección con Hipoclorito de Sodio al 3,5\% i.a., por 15 minutos en cámara de flujo laminar, agitándolos periódicamente, finalmente se realizaron tres enjuagues con agua destilada estéril. 


\section{Medios de cultivo}

Para la elaboración de los medios de cultivos se tomó como base el propuesto por Murashige y Skoog (1962) [6] con las sales y vitaminas completas, al cual se le adicionaron distintos reguladores de crecimiento según la etapa del proceso de embriogénesis somática indirecta. Detallados a continuación.

Inducción de callo

Se evalúo el efecto de tres reguladores de crecimiento los cuales fueron BAP $(0,5 \mathrm{mg} / \mathrm{L}$ y 2,0 $\mathrm{mg} / \mathrm{L})$, ANA (0,1 mg/L) y 2,4-D (0,5 mg/L y $2 \mathrm{mg} / \mathrm{L})$, así como Myo-inositol (0 y $100 \mathrm{mg} / \mathrm{L})$, que se adicionaron el medio de cultivo Murashige y Skoog (1962) [6] completo. La unidad experimental consistió en un explante por envase de cultivo, con 30 repeticiones y cada tratamiento se repitió tres veces (Cuadro 1). Los explantes fueron colocados en el cuarto de crecimiento en condiciones de oscuridad a una temperatura de $21^{\circ} \mathrm{C}$, realizando subcultivos cada quince días. Se evaluó el peso fresco de 30 callos al mes de cultivo para establecer el mejor medio de cultivo para la inducción de callogénesis, además se seleccionaron, con ayuda de un estereoscopio, los callos con apariencia embriogénica.

Cuadro 1. Composición de los medios de cultivo de tres tratamientos evaluados para la inducción de callogenesis a partir de la base de dientes de ajo (Allium sativum).

\begin{tabular}{|c|c|}
\hline Tratamientos & Composición \\
\hline T1 & $\begin{array}{r}\text { M\&S (1962) suplementado con 3\% de sacarosa, 2,0 mg/L de BAP, 1mg/L ANA, } \\
\text { 0,5mg/L de 2,4-D, y } 100 \mathrm{mg} / \mathrm{L} \text { de Myo-inositol }\end{array}$ \\
\hline T2 & $\begin{array}{c}\text { M\&S (1962) suplementado con 3\% de sacarosa, 2,0 mg/L de BAP y } 0,5 \mathrm{mg} / \mathrm{L} \text { de } \\
2,4-\mathrm{D}\end{array}$ \\
& $\begin{array}{c}\text { M\&S (1962) suplementado con 3\% de sacarosa, 0,5mg/L BAP y 2,0 mg/L de 2,4- } \\
\text { D. }\end{array}$ \\
\hline T3 & \\
\hline
\end{tabular}

\section{Proliferación del callo embriogénico}

Los medios para la proliferación de tejidos embriogénicos, maduración de embriones y germinación, fueron los descritos por Nasim y colaboradores [7].

La proliferación de los callos desarrollados en los respectivos tratamientos (Cuadro 1), se subcultivaron al medio de proliferación de callos embriogénicos que consistió en un M\&S (1962) enriquecido con $1,0 \mathrm{mg} / \mathrm{L}$ de BAP y $0,25 \mathrm{mg} / \mathrm{L}$ de $2,4-D$ por seis semanas a $21^{\circ} \mathrm{C}$ en un régimen lumínico de 16 hora luz. Se tomaron 100 mg de callo embriogénico como unidad experimental, para un total de 30 repeticiones por tratamiento.

\section{Maduración de embriones}

Luego de las seis semanas en el medio de proliferación, los callos se subcultivaron a un medio de maduración embriogénica el cual consistió en un medio M\&S (1962) suplementado con 0,5 $\mathrm{mg} / \mathrm{L}$ de $\mathrm{AG}_{3}$ por un periodo de ocho semanas a $21^{\circ} \mathrm{C}$ en un régimen lumínico de 16 hora luz.

\section{Germinación de embriones}

Transcurrido el periodo de maduración, los callos se subcultivaron en un medio M\&S (1962) enriquecido con $0,5 \mathrm{mg} / \mathrm{L}$ de BAP por cuatro semanas para la germinación de los embriones obtenidos en las etapas anteriores. Las condiciones de cultivo fueron de $21^{\circ} \mathrm{C}$ en un régimen lumínico de 16 horas luz. 


\section{Análisis estadístico}

Se utilizó el programa InfoStat@, para realizar las pruebas de normalidad con Shapiro-Wilks y un análisis de varianza que se ajuste a la normalidad de los datos obtenidos.

\section{Resultados}

Inducción de callo

La figura 1 muestra la formación de callos a partir de los meristemos radicales de la base del diente de ajo.



Figura 1. A) Meristemos radicales de ajo. B) Callos desarrollados a partir de los meristemos radicales.

La figura 2 muestra el peso fresco de los callos formados en los diferentes tratamientos evaluados, obteniéndose un valor de p>0,001 para la prueba de normalidad Shapiro-Wilks (modificada), por lo que se infiere que los datos no poseen una distribución normal. Por este motivo se procedió a realizar la prueba de varianza no paramétrica de Kruskal-Wallis que reflejó un valor de $p=0,0431$ por lo que se infirió con certeza estadística que las diferencias entre los pesos obtenidos en cada tratamiento son estadísticamente significativas. Determinándose que el tratamiento 1 presentó la mayor media para el peso fresco de los callos.

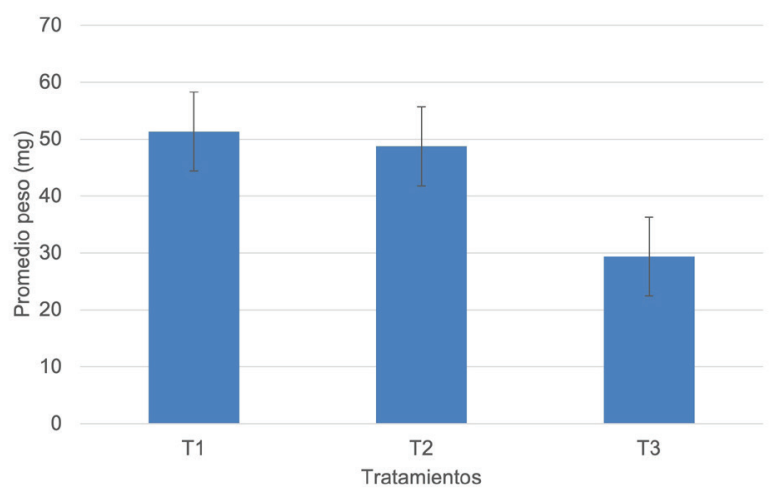

Figura 2. Pesos de los callos de Allium sativum, obtenidos en los tres tratamientos de inducción utilizados.

\section{Proliferación del callo embriogénico}

La figura 3 muestra que la proliferación de callos embriogénico es de $80 \%$ para los callos provenientes de los tratamientos T1 y T3 y 36,67\% para los callos inducidos en el tratamiento T2. 


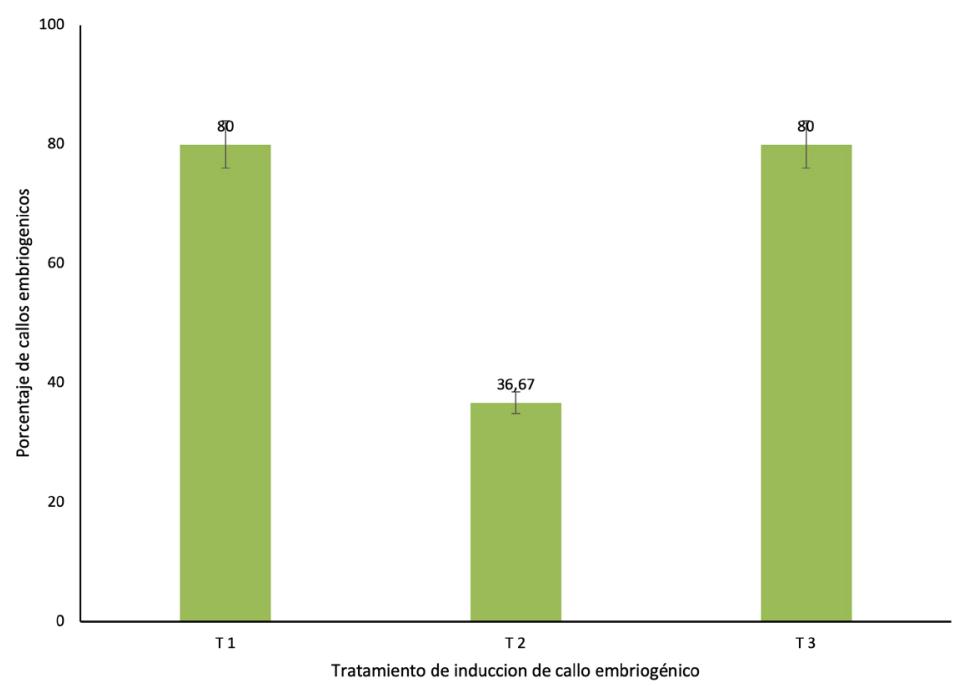

Figura 3. Porcentajes de proliferación de callos embriogénicos de Allium sativum, a partir de callos desarrollados en los tres tratamientos de inducción (cuadro 1) e inoculados en el medio proliferación.

A las seis semanas de subcutivo de los callos en el medio de proliferación se observó que en todos ellos se formaron numerosas estructuras de color blanco de formas alargadas y redondas correspondientes a tejido proembrionario y embriones inmaduros indistintamente del tratamiento de callogénesis que procedieran (figura 4).



Figura 4 A) Estructuras de tejido proembrionarios. B) Embriones inmaduros desarrollados a partir de estructura mostradas en la imagen A.

\section{Maduración de embriones}

A las seis semanas de subcultivar los callos que presentaban embriones inmaduros en el medio de maduración, se observó la elongación de los mismos, así como una coloración verde característica de la maduración. Además se observó, en menor medida, el desarrollo de estructuras no embrionarias identificadas como brotes y raíces (figura 4). 




Figura 5. A) Embriones somáticos maduros, B) brotes y C) raíces Allium sativum desarrollados a partir de callos obtenidos de meristemos radicales.

\section{Germinación de embriones}

Al subcultivar los embriones maduros en el medio de germinación se obtuvo a las cuatro semanas, el desarrollo de plántulas (figura 5 y 6 ).

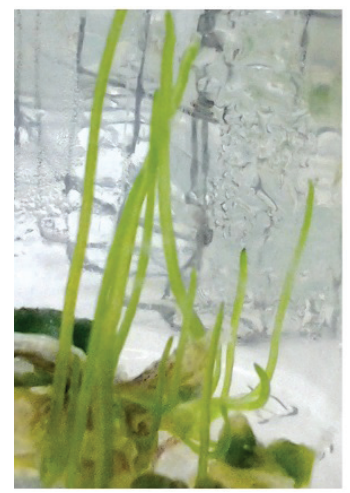

Figura 6. Plántulas de Allium sativum obtenidas a partir de embriones maduros cultivados en un medio de germinación.

\section{Discusión}

La unión de las auxinas a receptores en la pared celular desencadena una cascada de eventos que propician la secreción de protones acidificando el medio aumentando la presión de turgencia y activando proteínas que rompen los enlaces cruzados entre las moléculas de celulosa, permitiendo la elongación celular y los arreglos morfogénicos [8,5]. Llorente menciona que al utilizar combinación de auxinas se favorece la expansión y elongación celular, además de aumentar la plasticidad necesaria para procesos embriogénicos. De acuerdo con esto la diferencia entre los pesos frescos de los callos obtenidos en los distintos tratamientos, se debe a la combinación de las auxinas utilizadas.

Otro factor que influyó en el peso fresco de los callos obtenidos en el medio de cultivo 1, fue el Myo-inositol extra adicionado al medio de cultivo, debido a que actúa como segundo mensajero bajo la forma de trifosfato de inositol, durante el proceso de elongación y expansión celular inducido por las altas concentraciones de auxinas, requeridas para la desdiferenciación celular y la formación de callo [8]. 
La respuesta embriogénica diferencial observada en los callos de cada tratamiento, es determinada por la relación de las proporciones de las fitohormonas utilizadas durante todo el proceso, ya que estas mediaran en la respuesta morfogénica. Una concentración muy baja de auxinas no logra desencadenar la inducción del proceso embriogénico ya que el 2,4-D extracelular es necesario para la formación de callos embriogénicos [9].

Este estímulo de altas concentraciones de auxinas resulta en una mayor cantidad de células competentes, es decir células con la capacidad de diferenciarse en embriones al recibir inductores de diferenciación. Estas células pueden reconocerse morfológicamente y diferenciarse del resto de las células del callo, porque son pequeñas, redondeadas, con citoplasma denso, vacuolas pequeñas y el núcleo está situado en una posición central [10, 11].

La maduración embrionaria es el proceso durante el cual se culmina la histodiferenciación de los tejidos embrionarios. En esta etapa ocurren distintos procesos fisiológicos y morfológicos como la expansión celular y acumulación de sustancias de reserva. En muchos trabajos no se informa la existencia de esta fase, solo se mencionan la formación y germinación de embriones [12].

La presencia de embriones somáticos, así como de brotes y raíces en el mismo callo en la etapa de maduración, se debe por el consumo diferencial de auxinas y citoquininas por el explante. Las auxinas necesarias para la embriogénesis somática son consumidas de manera rápida y eficiente, en contraste a las citoquininas que son consumidas de manera más lenta. Si el callo se mantiene en el mismo medio una vez que las auxinas se agoten, el tejido pierde su potencial embriogénico y se da el inicio a la formación de embrioides en las células competentes, el resto de las células son influenciadas por el efecto de las citoquinas, que aún están presentes en el medio, por lo que se desarrollan en brotes y raíces [13]. En el caso específico de los callos obtenidos en este ensayo, al desarrollarse a partir de meristemos radicales, presentan una predisposición fisiológica y genética a desarrollar un proceso rizogénico al agotarse las reservas de auxinas exógena [14].

La germinación de los embriones consiste en el desarrollo de los meristemos radicales y foliares que culmina en la formación de una plántula completa. Esto fue posible por el BAP adicionado en el medio, ya que este regulador del crecimiento perteneciente a las citoquininas, favorece el crecimiento celular en las regiones polares del embrión, estimulando el desarrollo foliar y radical [15]. Este efecto ya ha sido observado en otros trabajos como los de Carhuaricra y colaboradores en la variedad de ajo Morado Barranquino donde fueron utilizadas distintas concentraciones de BAP para la regeneración in vitro de meristemos apicales de ajo [16] y en el trabajo de Carbajal-Cruz se utilizó en la germinación in vitro de plantas como metodología para la obtención de plantas libres de virus [17]"publisher":"Universidad Autónoma de Nuevo León","number-of-pages":"89","genre":"masters","source":"eprints.uanl.mx","abstract":"El virus del enanismo amarillo de la cebolla (OYDV.

\section{Conclusiones}

Se logró inducir y regenerar embriones somáticos a partir de meristemos radicales de ajo criollo costarricense.

Se determinó que el medio con 2,0 mg/L de BAP, 1mg/L ANA, 0,5 mg/L de 2,4-D, y $100 \mathrm{mg} / \mathrm{L}$ de Myo-inositol fue el mejor para la inducción de callos embriogénicos, ya que de este se obtuvieron los callos con un mayor peso fresco y la respuesta embriogénica más alta, al utilizar bases de diente de ajo como explante. 


\section{Recomendaciones}

Los autores recomiendan realizar ensayos con medio líquido en la etapa de proliferación, maduración y germinación para disminuir los costos de producción y aumentar los rendimientos.

Así mismo se recomiendan disminuir el tiempo de subcultivo de los callos en el medio de proliferación de tejido embriogénico para evitar el proceso organogénico en los mismos.

\section{Referencias}

[1] K. Barboza-Rojas, A. Hernández-Soto, y C. Zúñiga-Vega, «Semejanzas entre el ajo (Allium sativum) costarricense y el ajo asiático según secuencias de ADN ribosomal», 1, vol. 25, n. 2, p. ág. 32-40, ago. 2012.

[2] A. Guillén, C. Zúñiga, J. Brenes, L. Hilje, R. Chacón, y W. Rivera, Cultivo del ajo en Costa Rica. Costa Rica: EUNED, 2013

[3] L. Pérez Moreno, E. Palemón Alberto, S. Ayvar-Serna, y E. Cevallos Ruiz, «Adaptación de cultivares de ajo morado y blanco ("Allium sativum" L.) en Acatlán, Guerrero, México", Acta Universitaria, ISSN 0188-6266, Vol. 15, No. 1, 2005, pags. 55-65, vol. 15, pp. 55-65, ene. 2005.

[4] M. Reveles-Hernández, R. Velásquez-Valle, y Á. G. Bravo-Lozano, «Tecnología para el cultivar ajo en Zacatecas», p. 294, 2009.

[5] J. I. Cubero, Introducción a la mejora genética vegetal, 3a ed. España: Mundi-Prensa Libros, 2013.

[6] T. Murashige y F. Skoog, «A Revised Medium for Rapid Growth and Bio Assays with Tobacco Tissue Cultures», Physiol Plant, vol. 15, n. ${ }^{\circ}$, pp. 473-497, jul. 1962.

[7] S. A. Nasim, A. Mujib, R. Kapoor, S. Fatima, y J. Aslam, «Somatic embryogenesis in Allium sativum L. (cv. Yamuna Safed 3): Improving embryo maturation and germination with PGRs and carbohydrates», Anales de Biología, vol. 32, pp. 1-9, 2010.

[8] V. Parra Vega, «Aspectos básicos y aplicados de la inducción de embriogénesis en microsporas de pimiento y colza», Tesis Doctoral, Universitat Politécnica de Valéncia, España, 2015.

[9] E. Hernandez, «Embriogénesis somática in vitro y aclimatación de plántulas obtenidas por organogénesis directa en heliconia spp», Tesis Doctoral, Institución de Enseñanza e Investigación en Ciencias Agrícolas, México, 2013.

[10] A. Fehér, «The initiation phase of somatic embryogenesis: what we know and what we don't», Acta Biologica Szegediensis, vol. 52, pp. 53-56, 2008.

[11] X. Yang y X. Zhang, «Regulation of Somatic Embryogenesis in Higher Plants», Critical Reviews in Plant Sciences, vol. 29, n. ${ }^{\circ}$, pp. 36-57, ene. 2010.

[12] S. de J. Martínez et al., «Maduración y germinación de embriones somáticos de Sorghum bicolor (L.) Moench cultivar 'CIAP 132R-05'», Biotecnología Vegetal, vol. 17, n.ำ 1, mar. 2017.

[13] A. Lara, R. Valverde, y L. Gómez, «HISTOLOGÍA DE EMBRIONES SOMÁTICOS Y BROTES ADVENTICIOS», AGRONOMÍA COSTARRICENSE, vol. 27, pp. 37-48, 2003.

[14] A. Espinosa, J. Silva, S. Sariego, L. Cholo Masapanta, y H. Delgado, «Efecto del tipo de explante y la concentración de ácido 2,4-diclorofenoxiacético en la formación de callos en Morus alba L. », Pastos y Forrajes, vol. 35, n. ${ }^{\circ}$ 4, pp. 407-416, dic. 2012.

[15] F. Villanueva, M. Ávila, A. Mansilla, S. Abades, y J. Cáceres, «Efecto de auxinas y citoquininas en el cultivo de tejido de Ahnfeltia plicata (Hudson) Fries, 1836 (Ahnfeltiales, rhodophyta) de la región de magallanes», Anales del Instituto de la Patagonia, vol. 41, n. ${ }^{\circ}$ 1, pp. 99-111, 2013.

[16] K. Carhuaricra, J. Olivera, J. Gonzales, y J. Rodríguez, «Introducción y multiplicación in vitrodel cultivo de ajo variedad Morado Barranquino», Rev peru biol, vol. 19, n. 3, pp. 341-344, jun. 2013.

[17] N. N. Carbajal-Cruz, «Termoterapia y cultivo in vitro de ajo (Allium sativum L.) para la eliminación del virus del enanismo amarillo de la cebolla.», masters, Universidad Autónoma de Nuevo León, 2018. 